Page 1 of 13

This is the author's manuscript of the article published in final edited form as: Allen M. R., Burr D.B. (2008). Changes in vertebral strength-density and energy absorption-density relationships following bisphosphonate treatment in beagle dogs. Osteoporosis International, 19(1): 95-9. Available from: http://dx.doi.org/10.1007/s00198-007-0451-8

\section{Changes in vertebral strength-density and energy absorption- density relationships following bisphosphonate treatment in beagle dogs}

${ }^{1}$ Departments of Anatomy and Cell Biology and ${ }^{2}$ Orthopaedic Surgery, Indiana University School of Medicine

${ }^{3}$ Biomedical Engineering, Indiana University-Purdue University at Indianapolis

Send Correspondence to:

Matthew R. Allen, PhD

Dept. of Anatomy and Cell Biology, MS 5035

Indiana University School of Medicine

635 Barnhill Dr.

Indianapolis, IN 46202

Tel:

317-274-1283

FAX:

$317-278-2040$

Email: matallen@iupui.edu

Mini-Abstract: We aimed to determine the effects of bisphosphonates on mechanical properties independent of changes in bone density. Our results show that at equivalent bone densities, vertebrae from beagles treated with bisphosphonate have equivalent bone strength and reduced bone energy absorption compared to those from untreated animals. 
Page 2 of 13

\section{Abstract}

Introduction: Assessing the relationship between mechanical properties and bone density allows a biomechanical evaluation of bone quality, with differences at a given density indicative of altered quality. The purpose of this study was to evaluate the strength-density and energy absorption-density relationships in vertebral bone following one-year treatment with clinical doses of two different bisphosphonates in beagle dogs. Methods: Areal bone mineral density (aBMD) and compressive mechanical properties (ultimate load and energy absorption) were assessed on lumbar vertebrae from skeletally mature beagle dogs treated with vehicle (VEH), alendronate (ALN), or risedronate (RIS). Relationships among properties were assessed using analyses of covariance.

Results: Neither treatment altered the strength-density relationship compared to VEH, suggesting increases in vertebral strength with bisphosphonate-treatment are explained by increased density. The energy absorption-density relationship was altered by ALN, resulting in significantly lower energy absorption capacity at a given aBMD compared to both VEH (-22\%) and RIS (-14\%).

Conclusions: These data document that after adjusting for increased aBMD, vertebrae from animals treated with bisphosphonates have similar strength as those from untreated animals. Conversely, when adjusted for increased aBMD, alendronate treatment, but not risedronate treatment, significantly reduces the energy required for vertebral fracture, indicative of an alteration in bone quality.

KEYWORDS: Alendronate, Animal models, Mechanics, Risedronate 
Page 3 of 13

\section{Introduction}

Bone mineral density (BMD) provides a convenient means of assessing fracture risk, but it is well-accepted that skeletal factors other than BMD contribute to fracture prevention $(1,2)$. This is illustrated clinically by the disproportionate changes in BMD and fracture risk reduction with anti-remodeling treatments, with variable changes in BMD associated with similar reductions in fracture (3-5). Such data have led to numerous studies evaluating the effect of remodeling suppression on factors other than bone density that contribute to a bone's fracture resistance (6).

A bone's fracture resistance is determined by a combination of factors (7). For simplicity, these factors are oftentimes considered to include bone mass and "everything else". Bone mass can be variably defined, yet clinically is routinely measured as areal BMD (aBMD), a composite variable influenced by both bone mass (volume), bone size and mineralization. The "everything else", often encompassed by the term bone quality, includes factors such as whole bone geometry, microarchitecture, porosity, mineralization, collagen organization and cross-linking, and microdamage accumulation. Recently, Hernandez and Keaveny (6) proposed that bone quality can be defined by examining the relationship between measures of bone biomechanical performance and bone density, with a change in the relationship indicative of a change in bone quality. Any change in bone strength or energy to fracture not accounted for by a change in bone mass (aBMD) must be accounted for by other measures of bone as defined above (6). If a treatment has no effect on bone quality then the strength-density relationships would be similar to untreated bone. Conversely, if a treatment alters bone quality (either positively or negatively) then the strength-density curve would differ relative to untreated bone. 
Although this approach does not address which component of bone quality is altered, it does provide a useful starting point to determine if treatments alter biomechanical properties through density-dependent or density-independent mechanisms. We have previously documented that the bisphosphonates risedronate and alendronate increase the strength $(\sim 10 \%)$ and stiffness $(\sim 20 \%)$ of dog vertebrae following one-year treatment, but reduce toughness non-significantly at doses used for the clinical treatment of osteoporosis $(8,9)$, and significantly at doses used for the treatment of Paget's disease (10). The goal of this study was to determine if these anti-remodeling agents alter vertebral bone quality through assessment of the strength-density and energy absorption-density relationships.

\section{Methods}

Detailed methods regarding experimental design and tissue analyses have been previously reported $(8,9)$. Briefly, skeletally mature (range: 1-2 years old at initiation of study; mean age 1.3 years) female beagle dogs ( $n=36 ; 12$ group) were treated daily for 1 year with oral doses of saline vehicle (VEH), risedronate (RIS), or alendronate (ALN). The doses of RIS $(0.10 \mathrm{mg} / \mathrm{kg} /$ day $)$ and $\mathrm{ALN}(0.20 \mathrm{mg} / \mathrm{kg} /$ day $)$ represent the doses used to treat post-menopausal osteoporosis on a $\mathrm{mg} / \mathrm{kg}$ basis. Following one year of treatment, the fourth lumbar vertebra was excised and assessed for areal bone mineral density (aBMD, PIXImus densitometer). We chose to assess relationships using aBMD as this technique is used clinically to evaluate vertebrae bone density. Following endplate removal, bones were tested in compression $(10 \mathrm{~mm} / \mathrm{min})$ to determine mechanical properties. Ultimate load was defined as the maximal load achieved during the test, while energy absorption was defined as the area under the load/displacement curve up to 
100 the point of ultimate load. The strength-density and energy absorption-density

101 relationships were compared among groups using analyses of covariance. When groups

102 had similar slopes, least square means (LSM) were compared to determine differences in

103 parameters after accounting for aBMD. For all tests, $\mathrm{p}<0.05$ was considered

104 significant.

105

106 Results

107 As previously described, vertebral aBMD was significantly increased with ALN (0.36 + $\left.1080.02 \mathrm{~g} / \mathrm{cm}^{2}\right)$, but not RIS $\left(0.33+0.02 \mathrm{~g} / \mathrm{cm}^{2}\right)$, compared to VEH $\left(0.33+0.02 \mathrm{~g} / \mathrm{cm}^{2}\right)(8)$.

109 There was no significant difference in the strength-density relationship between VEH (y $110=17264 \mathrm{x}-1927.2$ ) and either RIS or ALN nor between the two bisphosphonates together $111 \quad($ pooled $y=16709 x-1724.8)$ (Figure 1A).

112 There was no significant difference among groups in the slope of the energy

113 absorption-density relationship, yet the intercepts differed significantly (Figure 1B).

114 After adjusting for aBMD, the energy absorption capacity was significantly lower in

115 ALN-treated specimens compared to both VEH $(\mathrm{LSM}=-22 \%, \mathrm{p}=0.02)$ and RIS (LSM

$116=-14 \%, p=0.02)$. There was no significant difference between VEH and RIS $(p=0.12)$

117 for energy absorption after accounting for differences in aBMD.

119 Discussion

120 Anti-remodeling agents are clearly beneficial for reducing fracture risk in post-

121 menopausal osteoporotic women, as well as various other populations. Despite this clear

122 efficacy, the mechanism of fracture risk reduction with these agents is poorly understood 
Page 6 of 13

123 beyond the suppression of osteoclast activity. The current study shows that any change

124 in vertebral bone strength with bisphosphonate-treatment can be explained entirely by

125 increased density. Additionally, these data show that alendronate-treated bone, but not

126 risedronate-treated bone, required significantly less energy to fracture than untreated

127 controls at a given bone density.

128 The current study shows bisphosphonates enhance compressive vertebral bone

129 strength by increasing bone density: the regression line depicting the strength-density

130 relationship is not significantly different for either RIS or ALN treatments compared to

131 VEH. As we have previously noted, the increases in vertebral compressive strength with

132 ALN and RIS were $10 \%$ and $9.5 \%$, respectively, both non-significant (8). We have also

133 previously reported no difference in the ultimate load to aBMD ratio between vehicle-

134 and bisphosphonate-treated specimens (9). Assessing the relationship between

135 biomechanical properties using the current method (regression analyses) as opposed to

136 using the ratio of strength/density of each specimen provides different information, yet

137 the two are not mutually exclusive (6). If the relationships are linear, with non-zero

138 intercepts (as they are here, see Figure 1), or if the relationships are non-linear, the ratios

139 can differ even when the data follow the same relationship. It is therefore important to

140 use both approaches (ratios and strength-density plots) to comprehensively assess

141 changes in bone quality.

142 In addition to bone strength, the energy absorption capacity of a bone is important

143 to determine fracture resistance (11). After accounting for increased density with

144 alendronate-treatment, the energy absorption capacity is significantly impaired compared

145 to specimens from animals treated with VEH (-22\%) and RIS (-14\%). This is contrasted 
146

147

148

to risedronate-treatment, which did not significantly alter the energy absorption-density relationship compared to vehicle. The reduced energy absorption capacity per unit aBMD in ALN-treated animals is consistent with previous results showing a trend toward reduced bone toughness, the tissue's ability to absorb energy, at doses used for the treatment of osteoporosis (9) and significant reductions in toughness at doses used for the treatment of Paget's disease (10). This suggests an additional increment in vertebral BMD is necessary with alendronate treatment to maintain energy absorption capacity at a level comparable to non-treated bone.

These data emphasize the importance of examining changes in numerous biomechanical properties, as the relationships between strength and density, and between energy to failure with density, were different for a given treatment. In addition, it remains unclear whether bone strength, energy absorption, or some other biomechanical parameter is most directly related to clinical fracture risk of the spine. Bone strength and energy absorption are believed to be governed by different parameters. The mineral component plays a significant role in determining the pre-yield properties of bone -strength and stiffness $(12,13)$, whereas the organic component dominates the post-yield deformation that accounts for energy absorption (14). Therefore, treatment-induced changes in mineral- or collagen-related bone quality parameters may only manifest in those biomechanical properties in which each is predominant. Numerous studies (15-17) have shown that bisphosphonates increase average tissue mineralization as well as mineralization homogeneity. This is consistent with our data that show increased strength associated with increased aBMD following bisphosphonate treatment. We have shown alterations to collagen maturity and cross-linking of vertebral bone in dogs 
following 1 year treatment with bisphosphonates (18). The non-enzymatic glycation of bone caused by bisphosphonate treatment has been shown to reduce post-yield deformation of bone (19). Increased formation of non-enzymatically-mediated cross links (such as pentosidine) is consistent with the aBMD-normalized reduction in energy to fracture demonstrated here. Changes in microarchitecture could also play a role, as even with similar bone volumes, subtle changes in the trabecular architecture could alter various mechanical properties including energy absorption $(20,21)$.

In clinical trials, alendronate has been shown to produce greater remodeling suppression than risedronate (22). Analyses of turnover suppression in the canine vertebrae in this study showed similar suppression at potency-equivalent doses of ALN and RIS relative to VEH-treated animals (-66 and 74\%, respectively) (8). Differences in turnover rates, or rather the degree of turnover suppression, would produce differences in microarchitecture as well as properties of the material that are dictated by remodeling rate (e.g. mineralization, collagen cross-linking, and microdamage). Whether these nonsignificant differences in turnover suppression between ALN and RIS in this study account for the different results with respect to the aBMD-energy absorption relationship is unclear.

These data should be considered in the context of various limitations. The use of intact, non-ovariectomized beagle dogs may limit the translation of these results to postmenopausal women. In addition, we have also only assessed one site (vertebra) and therefore cannot definitively state whether these changes in bone quality are applicable to other clinically-relevant bone sites. Finally, as the goal of this study was to determine to relative contribution of aBMD and 'everything else' to the whole bone mechanical 
192 properties, these data do not specifically address the mechanism by which alendronate 193 reduces bone quality with respect to energy absorption. To address such issues, specific 194 material-level mechanical tests such as those using samples with defined geometry or 195 micro-mechanical tests including nanoindentation, are necessary. In conclusion, these data document bisphosphonates exert a positive effect on 197 vertebral bone strength through increases in density. The data also show that 198 alendronate, but not risedronate, significantly reduces vertebral energy required to 199 fracture, when normalized by bone density. Given the known role of the organic matrix 200 in determining energy absorption capacity, some effort should be made to determine the 201 effects of bisphosphonate treatment on the amount, maturity and cross-linking of the 202 collagen moiety in bone matrix and its role in altering mechanical properties. 
Page 10 of 13

204 Acknowledgements

205 The authors thank Dr. Tony Keaveny for insightful discussion regarding the topics

206 addressed in this paper. This work was supported by NIH Grants AR047838 and

207 AR007581 and a research grant from The Alliance for Better Bone Health (Procter \&

208 Gamble Pharmaceuticals and sanofi-aventis). Merck and Co. kindly provided the

209 alendronate. This investigation utilized an animal facility constructed with support from

210 Research Facilities Improvement Program Grant Number C06 RR10601-01 from the

211 National Center for Research Resources, National Institutes of Health.

212

213

214

215

216 


\section{$217 \quad$ Figure Legend.}

218 Figure 1. Strength-density (A) and energy absorption-density (B) relationships of

219 vertebral bone from beagles treated for 1 year with vehicle or clinical doses of

220 risedronate, or alendronate. The strength-density relationship was similar for untreated

221 (vehicle $(\bullet), \mathrm{y}=17264 \mathrm{x}-1927.2)$ and bisphosphonate-treated animals (pooled $(0), \mathrm{y}=$

$22216709 \mathrm{x}-1724.8)$. BP-treated groups were combined as there was no difference between

223 RIS $(y=24551 x-4132)$ and $\operatorname{ALN}(y=10051 x+464)$ for the strength-density

224 relationship. The energy absorption-density relationship differed from untreated $(\bullet, \mathrm{y}=$

$2259717 \mathrm{x}-1437)$ and risedronate-treated $(\boldsymbol{\nabla}, \mathrm{y}=12559 \mathrm{x}-2604)$ animals compared to

226 those treated with alendronate $(0, y=8542 x-1439)$. 


\section{References}

1. Delmas PD, Li, Z, Cooper, C (2004) Relationship between changes in bone mineral density and fracture risk reduction with antiresorptive drugs: some issues with metaanalyses. J Bone Miner Res 19:330-337.

2. Delmas PD, Seeman, E (2004) Changes in bone mineral density explain little of the reduction in vertebral or nonvertebral fracture risk with anti-resorptive therapy. Bone 34:599-604.

3. Black DM, Cummings, SR, Karpf, DB, Cauley, JA, Thompson, DE, Nevitt, MC, Bauer, DC, Genant, HK, Haskell, WL, Marcus, R, Ott, SM, Torner, JC, Quandt, SA, Reiss, TF, Ensrud, KE (1996) Randomized trial of effect of alendronate on risk of fracture in women with existing vertebral fractures. Fracture Intervention Trial Research Group. Lancet 348:1535-1541.

4. Ettinger B, Black, DM, Mitlak, BH, Knickerbocker, RK, Nickelsen, T, Genant, HK, Christiansen, C, Delmas, PD, Zanchetta, JR, Stakkestad, J, Gluer, CC, Krueger, K, Cohen, FJ, Eckert, S, Ensrud, KE, Avioli, LV, Lips, P, Cummings, SR (1999) Reduction of vertebral fracture risk in postmenopausal women with osteoporosis treated with raloxifene: results from a 3-year randomized clinical trial. Multiple Outcomes of Raloxifene Evaluation (MORE) Investigators. JAMA 282:637-645.

5. Harris ST, Watts, NB, Genant, HK, McKeever, CD, Hangartner, T, Keller, M, Chesnut, CH, 3rd, Brown, J, Eriksen, EF, Hoseyni, MS, Axelrod, DW, Miller, PD (1999) Effects of risedronate treatment on vertebral and nonvertebral fractures in women with postmenopausal osteoporosis: a randomized controlled trial. Vertebral Efficacy With Risedronate Therapy (VERT) Study Group. JAMA 282:1344-1352.

6. Hernandez C, Keaveny, T (2006) A biomechanical perspective on bone quality. Bone 39:1173-1181.

7. Turner CH, Burr, DB (1993) Basic biomechanical measurements of bone: a tutorial. Bone 14:595-608.

8. Allen MR, Iwata, K, Phipps, R, Burr, DB (2006) Alterations in canine vertebral bone turnover, microdamage accumulation, and biomechanical properties following 1-year treatment with clinical treatment doses of risedronate or alendronate. Bone 39:872-879. 9. Allen MR, Iwata, K, Sato, M, Burr, DB (2006) Raloxifene enhances vertebral mechanical properties independent of bone density. Bone 39:1130-1135. 10. Mashiba T, Turner, CH, Hirano, T, Forwood, MR, Johnston, CC, Burr, DB (2001) Effects of suppressed bone turnover by bisphosphonates on microdamage accumulation and biomechanical properties in clinically relevant skeletal sites in beagles. Bone 28:524531 .

11. Currey JD (2001) Bone strength: what are we trying to measure? Calcif Tissue Int 68:205-210.

12. Currey JD (2004) Tensile yield in compact bone is determined by strain, post-yield behaviour by mineral content. J Biomech 37:549-556.

13. Currey JD, Brear, K, Zioupos, $P$ (1996) The effects of ageing and changes in mineral content in degrading the toughness of human femora. J Biomech 29:257-260. 14. Burr D (2002) The contribution of the organic matrix to bone's material properties. Bone 31:8-11. 
15. Boivin GY, Chavassieux, PM, Santora, AC, Yates, J, Meunier, PJ (2000) Alendronate increases bone strength by increasing the mean degree of mineralization of bone tissue in osteoporotic women. Bone 27:687-694.

16. Roschger P, Rinnerthaler, S, Yates, J, Rodan, GA, Fratzl, P, Klaushofer, K (2001) Alendronate increases degree and uniformity of mineralization in cancellous bone and decreases the porosity in cortical bone of osteoporotic women. Bone 29:185-191. 17. Zoehrer R, Roschger, P, Paschalis, EP, Hofstaetter, JG, Durchschlag, E, Fratzl, P, Phipps, R, Klaushofer, K (2006) Effects of 3- and 5-year treatment with risedronate on bone mineralization density distribution in triple biopsies of the iliac crest in postmenopausal women. J Bone Miner Res 21:1106-1112. 18. Gineyts E, Allen, MR, Burr, DB, Delmas, PD (2006) Effects of Antiresorptive Therapy on the Bone Tissue Concentration of Enzymatic Mature Collagen Crosslinks and Pentosidine. J Bone Miner Res 21 (Supp 1):M344.

19. Vashishth $\mathrm{D}, \mathrm{Wu}, \mathrm{P}$, Gibson, G (2004) Age-related loss in bone toughness is explained by non-enzymatic glycation of collagen. Trans Orthop Res Soc 29. 20. Hernandez CJ, Gupta, A, Keaveny, TM (2006) A biomechanical analysis of the effects of resorption cavities on cancellous bone strength. J Bone Miner Res 21:12481255.

21. Wachter NJ, Augat, P, Mentzel, M, Sarkar, MR, Krischak, GD, Kinzl, L, Claes, LE (2001) Predictive value of bone mineral density and morphology determined by peripheral quantitative computed tomography for cancellous bone strength of the proximal femur. Bone 28:133-139.

22. Rosen CJ, Hochberg, MC, Bonnick, SL, McClung, M, Miller, P, Broy, S, Kagan, R, Chen, E, Petruschke, RA, Thompson, DE, de Papp, AE (2005) Treatment with onceweekly alendronate $70 \mathrm{mg}$ compared with once-weekly risedronate $35 \mathrm{mg}$ in women with postmenopausal osteoporosis: a randomized double-blind study. J Bone Miner Res 20:141-151. 

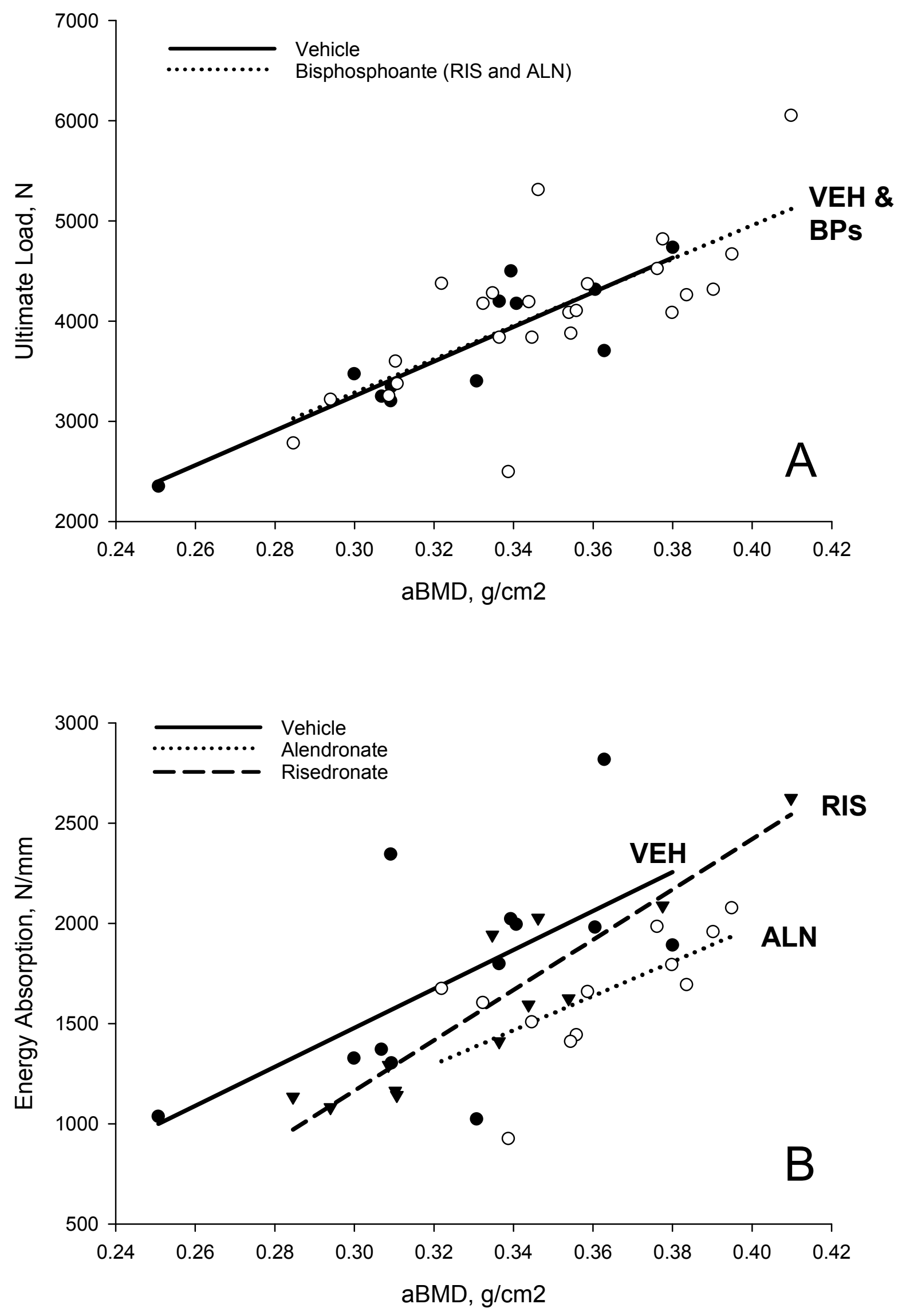

http://mc.manuscriptcentral.com/oi 